In their experience the literature on protection is not readily available; but a competent engineer can solve his problems by common sense and by insisting on a rigid discipline among the operating staff.

The legal responsibility for the health and welfare of workers in factories, but not in research laboratories, lies with the Ministry of Labour. Mr. K. Goodall (H.M. inspectorate of factories) described how this Ministry watches for new hazards and advises on old ones. In the case of sealed sources of radioactive isotopes, the position is at present satisfactory in that the Ministry is informed from Harwell or Amersham of the delivery of all such consignments to new customers. Present records show surprisingly few accidents, and Dr. Ethel Browning's hæmatological data contain few abnormalities. With the existing policy of persuasion, results are as satisfactory as would be expected if regulations were in force; the greatest danger, said Mr. Goodall, still remains not the closed sources of radioactivity but the open sources met with in the luminizing industry.

In industry, according to the evidence presented, the care or discipline exercised has resulted in the workers receiving doses well below tolerance (an average of about $10 \mathrm{mr}$./week in one case). By contrast, in the Ordnance Inspectorate of the Royal Navy, as it appeared from Commander P. Chandler's remarks at the meeting, policy is determined by the delivery of the goods and not by the hazard to the staff. This attitude may be necessary in the Armed Forces in time of war, but was alarming to the medical section of the audience.

\section{ROYAL ASTRONOMICAL SOCIETY}

\section{PRESENTATION OF GOLD MEDAL}

A

T the meeting of the Royal Astronomical Society on February 8, 1952, at Burlington House, London, the Gold Medal of the Society was presented to Dr. John Jackson by Prof. H. Dingle, the president of the Society, who gave an address which has since been published in full (Mon. Not. Roy. Astro. Soc., $112,3 ; 1952)$.

Not very long after Dr. Jackson had finished his career at Cambridge he went, in 1914, as chief assistant to the Royal Observatory, Greenwich, where about twenty years of work on double stars with the 28-in. refractor awaited analysis, and this task was undertaken by Jackson in collaboration with Furner. There were also available F. G. W. Struve's results, published in 1837, which included 3,112 close pairs, and many more were added by the late Otto Struve, who continued his father's work. Jackson showed that 649 of F. G. W. Struve's stars had changed their configuration since his day; of these, 449 showed true orbital motion, 161 were optical doubles the components of which differed in proper motion, and in 39 the nature of the motion was uncertain. Among Otto Struve's stars he found that 135 wore binaries, 15 optical doubles and 5 had doubtful motion. 'The results of the analysis were published in a number of papers in Monthly Notices of the Royal Astronomical Society from 1920 onwards, and the hypothetical parallaxes deduced agreed well with the trigonometric and spectroscopic parallaxes which were then available. The next step was the determination of the cross-components of the velocities of the stars from their known proper motions, from which the apex and speed of the solar motion were determined, and these showed good agreement with those found by other methods. The absolute magnitudes of the stars were also determined from their apparent magnitudes, and this provided further evidence for the separation of the stars of the later spectral type into giants and dwarfs, which had been investigated by Hertzsprung and Russell some years previously and gave strong support to Russell's theory of stellar evolution.

During 1924-30 Jackson carried out valuable work on time measurement. Two Shortt free-pendulum clocks, the running of which was in charge of $W$. Bowyer, acting under Jackson's direction, were installed at the Royal Observatory in 1924 and 1926 , and four papers on their behaviour up to the end of 1930 appeared in the Monthly Notices. An analysis of the errors showed that these could be reduced to three terms, one due to nutation causing nonuniformity of sidereal time, another arising from temperature fluctuations, and the third-the 'secular term'- the origin of which was not immediately obvious but which was later attributed to a gradual increase in the length of the invar rod of the free pendulum. Other possible causes, however, were conceivable, and subsequent observations cast doubts on the supposition that the gradual growth of the invar rod was the main cause of the secular term. The conclusion was that the most that could be hoped from these clocks in detecting fluctuations in the earth's rotation was that they might determine whether erratic changes of $1 \cdot 0^{\prime \prime}$ a year in the moon's longitude could be due to irregularities in the earth's rotation period. One very valuable result of the whole investigation was the discovery of the nutation effect, showing the necessity for distinguishing between apparent and mean sidereal time.

In 1930 Jackson published an analysis of observations made with the Greenwich Cookson zenith telescope; this indicated that the value of the constant of nutation was $9 \cdot 2066^{\prime \prime} \pm 0 \cdot 0055^{\prime \prime}$, which was smaller than the value used in the ephemerides. The latter, based on Newcomb's determination from a very long series of observations, agreed very well with a more recent determination by Przybyllok, and a discordance between this and the theoretical value, considerably larger than the probable error, requires some explanation. Jackson regarded it as "one of the outstanding discordances of the constants of the solar system"; but, as Prof. Dingle remarked in his address, it is unlikely that the last word has yet been said concerning the theoretical value.

In 1925 Jackson began to collaborate with KnoxShaw and Robinson, of the Radeliffe Observatory, Oxford, on the reduction of Hornsby's meridian observations. The observations selected for reduction were those made between 1774 and 1798, and included about 43,000 observations of stars, 5,200 of the sun, 4,600 of planets, and 1,200 of the moon. From the results it was possible to apply systematic corrections to Boss's "Catalogue" and also to Newcomb's tables of the sun's longitude, and to other elements of the sun's apparent orbit about the earth-the equinox, the obliquity, the eccentricity and the longitude of perigee. The main publication appeared in 1932 and was followed with a paper in the Monthly Notices on the observations of Mercury; these observations were specially important in checking the motion of the planet's perihelion.

In 1933 Dr. Jackson succeeded Sir Harold Spencer Jones as His Majesty's Astronomer at the Cape of Good Hope, and until his retirement in 1950 his work 
there followed the main lines laid down by his predecessor. The programme consisted of three parts : the parallax work, the determination of positions and proper motions of stars in the Cape astrographical zones, and the compilation of a "Photographic Zone Catalogue" for the region $-30^{\circ}$ to $-90^{\circ}$ in declination. Spencer Jones's programme, inaugurated in 1926, was the measurement of the parallaxes of all possible stars of proper motion exceeding $40^{\prime \prime}$ a century south of declination $-10^{\circ}$. Although a number of determinations had been made when Jackson assumed office, the greater part of the programme remained to be executed, and results were published from time to time in the Monthly Notices and in three successive volumes of the Cape Annals, which were edited by Jackson. In his annual report for 1949 Jackson announced that 1,623 parallaxes had been determined since the work started and that it was then almost completed. The results of the second part of the programme were published in 1936 under the titles "Proper Motions of Stars in the Zone Catalogue of 20,843 Stars, 1900, Zones $-40^{\circ}$ to $-52^{\circ}$, derived from the Photographs taken at the Royal Observatory, Cape of Good Hope", and in 1939 in "Catalogue of 20,554 Faint Stars in the Cape Astrographic Zone $-40^{\circ}$ to $-52^{\circ}$, for the Equinox of $1900 \cdot 0$, giving Positions, Precessions, Proper Motions and Photographic Magnitudes, derived from Photographs taken at the Royal Observatory, Cape of Good Hope". Many important statistical results were derived from this study of more than forty thousand southern stars, and the information obtained has an important significance for the future. Good progress has also been made on the third part of the programme, the compilation of a "Photographic Zone Catalogue". for the region - $30^{\circ}$ to $-60^{\circ}$ in declination, with the wide-angle cameras, in which programme magnitudes and colours have also been included.

Prof. Dingle referred also in his address to a number of other tasks which Dr. Jackson has undertaken at the Cape; but it is sufficient in this résumé to quote Prof. Dingle's words that "The Gold Medal of our Society is bestowed for outstanding excellence of astronomical work, and for nothing else".

\section{BRITISH DEPENDENCIES IN THE CARIBBEAN AND NORTH ATLANTIC}

$\mathrm{P}$

ROF. W. M. MACMILLAN'S "Warning from the West Indies" was published in 1936: the 'warning' of the book's title, he wrote later, was "originally an appeal, and looked to the future". How far his warnings and those of others have been heeded may be judged by a recently issued Colonial Office publication* which surveys the history of the British territories in the Caribbean and North Atlantic during the past thirteen years. It is the fourth in a series of official reports designed to take a longer view of trends and developments than is possible in the various annual Colonial reports. The previous reports have covered the post-war period in the Far East (Cmd. 7709, 1949), East and Central Africa (Cmd. 7987, 1950), and the British islands in *Colonial Office. "British Dependencies in the Caribbean and
North Atlantic, 1939-1952." (Cmd. 8575.) $\mathrm{Pp}$. xi +98 . (London: H.M.S.O., 1952.) 38, 6d. net. the southern hemisphere (Cmd. 8230, 1951). The present report extends its range backwards to 1939 and even earlier, and it does so wisely, for the situation to-day in these areas is so dependent on the circumstances of the inter-war and war years that it is impossible to understand it without reference to this background.

This point is clearly made in the first chapter of the report, "The Seeds of the Present", which summarizes the position in the period preceding the appointment of the West Indies Royal Commission of 1938-39 and the results of that Commission, and reviews the events of the war-years that followed. The Commission decided that the region was in urgent need of social services which it could not afford from its own resources or from any unassisted development of these resources that was likely in the near future. Considerations such as these in the Colonial Empire generally lay behind the establishment of the Colonial Development and Welfare Fund in 1940: in the West Indies a Development and Welfare Organization was set up with the late Sir Frank Stockdale as its first comptroller and, despite war-time shortages, much re-organization and rehabilitation were carried through. Although, as the report puts it, "the impact of the war was manifold and serious", the end of the War left the West Indies with their basic economy largely intact and with good prospects for the planning of the future.

The chapters that follow and the useful statistical appendixes present a synoptic view of the situation to-day. The survey of political and constitutional development indicates the diversity of political structure and the complexity of local government, as well as the variety of ways in which advance is being made in the different territories from representative to responsible government. It also explains both the difficulties and the prospects of federation, towards which there is a distinct movement in most of the islands and about which a further conference is to be held in London in April.

The economic outlook just before the Second World War was, to quote the Royal Commission, "not at all reassuring", on account of the depression in the main primary-producing occupations of the region and because of the problems resulting from the high natural rate of increase of population. To-day the report states that "the uncertainty of the inter-war years has gone", partly through the development of new markets and of systems of guaranteed prices, and partly because of action taken under the Development and Welfare Acts to strengthen the region's economy, particularly its agriculture. At the same time, some of the economic problems have been intensified: developments in preventive medicine, in particular, by increasing the rate of growth of population, are already increasing the demand for education and for employment. The necessity for "the more intensive use of the land with increased production of food" is as great to-day as when the Royal Commission expressed this need, and it is satisfactory to learn that since 1939 there has emerged a new approach to the question of the most efficient use of the land, for foodstuffs as well as for export crops such as sugar, cocoa and bananas. There has been progress, too, in animal husbandry, forestry, the processing and other industries, and mining (British Guiana is the world's second largest producer of bauxite, which is also now being mined in Jamaica with the financial assistance of the Economic Co-operation Administration of the United 